
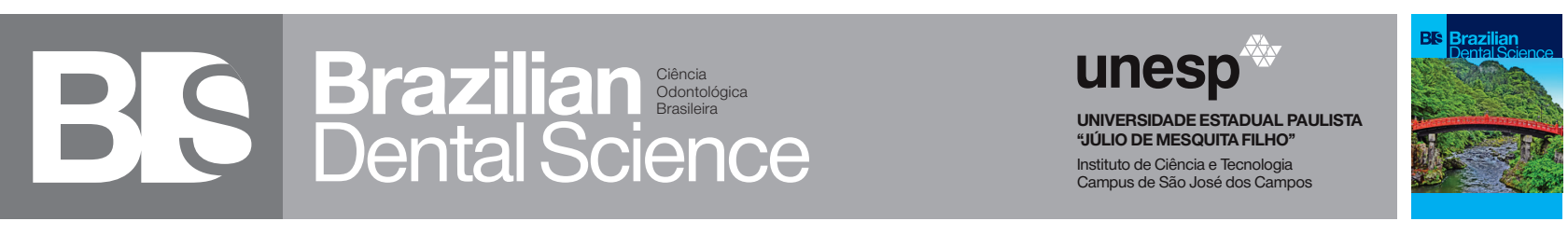

\title{
Prevalence of foramen tympanicum (or of huschke) in a brazilian population: a cone beam computed tomography study
}

Prevalência do forame timpânico (ou de Huschke) em uma população brasileira: estudo por Tomografia Computadorizada de Feixe Cônico.

Annamaria Teixeira LIMA ${ }^{1}$, Thais Camargo LEME ${ }^{1}$, Ana Amélia BARBIERI ${ }^{2}$, Afonso Celso Souza ASSIS ${ }^{1}$, Luiz Roberto Coutinho MANHÃES JÚNIOR ${ }^{1}$, Sérgio Lúcio Pereira de Castro LOPES ${ }^{1}$

1 - São Paulo State University (UNESP) - Institute of Science and Technology - São José dos Campos - Department of Diagnosis and Surgery, SP, Brazil.

2 - São Paulo State University (UNESP) - Institute of Science and Technology - São José dos Campos - Department of Social and Paediatric Dentistry - São José dos Campos, SP, Brazil.

\section{ABSTRACT}

Objective: To study the prevalence of foramen of Huschke (FH) or foramen tympanicum (FT) in a Brazilian population by means of cone beam computed tomography (CBCT). Material \& Methods: 303 tomographic examinations were selected from an oral radiology clinic's archive, totalising 606 temporomandibular joints (TMJs), all acquired with an I-CAT CBCT scanner (Next Generation, Imaging Science International, Hatfield, PA, USA) operating at voxel size of $0.25 \mathrm{~mm}$ and field of view (FoV) between 6.0 to 8.0-cm height to encompass the mid-third of the face. The images were analysed by using XORAN software (Xoran Technologies, Ann Arbor, Michigan, USA) on a multiplanar reconstruction window, in which the entire tympanic region (right and left) was individually scanned in the supero-inferior orientation for presence of FH through axial sections. Results: Considering the total sample, we observed a prevalence of 14 foramens (2.27\%), with FT being more prevalent in females than in males (respectively, $1.46 \%$ and $0.81 \%$ ); as for age, we found a higher prevalence of FT in males aged between 0 and 20 years old (0.33\%) and in females older than 70 years old ( $0.66 \%)$; and as for the affected side, that is, presence of unilateral or bilateral FT, we found that $0.65 \%$ of the examinations had unilateral FT, whereas $1.62 \%$ had bilateral FT. Conclusion: FT had a prevalence of $2.27 \%$ in our sample, with females being more affected than males and highly prevalent $(0.66 \%)$ in women older than 70 years old.

\section{KEYWORDS}

Temporal bone; Cone beam computed tomography; Anatomical variation.

\section{RESUMO}

Objetivo: Estudo da prevalência do Forame de Huschke (FH) ou Timpânico (FT) em uma população brasileira, por meio de Tomografia Computadorizada de Feixe Cônico (TCFC). Material e Métodos: Foram selecionados 303 exames (606 articulações temporomandibulares - ATM) de TCFC, do arquivo de uma clinica de Radiologia Odontológica, em uma instituição pública, adquiridos em tomógrafo da marca I-CAT Next Generation (Imaging Science International, Hatfield, PA, EUA), com FOV (Campo de Visão) englobando o terço médio da face (entre 6,0 a $8,0 \mathrm{~cm}$ de altura) e voxel de $0,25 \mathrm{~mm}$. As imagens foram analisadas na janela de reconstrução multiplanar (MPR) no software XORAN (Xoran Technologies, Ann Arbor, Michigan, EUA), sendo realizada uma varredura de toda a região timpânica (direita e esquerda) individualmente, no sentido supero-inferior dos cortes axiais, para verificar a presença FH. Resultados: Considerandose o total da amostra, foi observada uma prevalência de 14 forames $(2,27 \%)$, tendo maior prevalência do FT no gênero feminino sobre o masculino (1,46\% e $0,81 \%$ da amostra, respectivamente); quanto à idade, podemos indicar que maior prevalência da ocorrência do FT foi em homens de 0 a 20 anos $(0,33 \%)$ e acima dos 70 anos para mulheres $(0,66 \%)$ e quanto ao lado afetado pela presença do FT - unilateral direito ou esquerdo-ou bilateral, encontramos que $0,65 \%$ dos exames da amostra apresentavam-se unilaterais, enquanto $1,62 \%$ no total, bilaterais. Conclusão: O FT apresentou uma prevalência de $2,27 \%$ na amostra, sendo o gênero feminino o mais acometido, com alta prevalência $(0,66 \%)$ neste, acima dos 70 anos.

\section{PALAVRAS-CHAVE}

Osso temporal; Tomografia computadorizada de feixe cônico; Variação anatômica. 


\section{INTRODUCTION}

$\mathrm{H}$ mil mil Huschke (1797-1858), in his 1844 publication of "Sömmering's Anatomie dês Menschen", described an opening which was occluded by a fibrous membrane in the tympanic plate in an infant, which was then known as Foramen of Huschke [1]. The foramen of Huschke (FH) is formed following the birth, when the tympanic ring becomes an uninterrupted ring-shape tympanic bone at its upper extremity. During its development, which occurs in the superior-circular sense by means of ossifying centres, the tympanic bone will fuse to the petrous portion of the temporal bone to form the external wall of the tympanic cavity.

In the next developmental phase, there is an emergence of two tubercles or prominences growing one against another until becoming joined together in the first year of life. The tympanic bone presents now, as a result of the fusion of these two tubercles, an opening called foramen tympanicum or foramen de Huschke [2].

The tympanic plate (TP) grows and the tympanic foramen becomes gradually closed until the fifth year of life. This process is influenced by mechanical factors such as mastication, deglutition and breathing [3]. However, due to a defect in the normal ossification, the foramen may sporadically remain over the life [4].

TP is located between the squamous part and mastoid temporal bone, forming the anterior wall, floor and lower part of the posterior wall of the external auditory meatus (EAM). FH is located in the antero-inferior wall of the EAM in the TP of the temporal bone, showing a communication between meatus and mandibular fossa [5]. Anatomically, however, $\mathrm{FH}$ is not an actual foramen as there is no neurovascular structure passing through it.

$\mathrm{FH}$ is more frequently asymptomatic and may be overlooked. Its clinical importance has been recognised and several authors call attention to this fact, stating that this anomaly may be a potential route for dissemination of infections originating from EAM, which can affect the temporomandibular joint and parotid gland; tumours originating in the joint fossa, which uncommonly may reach the EAM; cases of spontaneous salivary fistula in the same auditory meatus; and complications in the arthroscopy of temporomandibular joint (TMJ).

In symptomatic patients, one can usually observe painful foramen, temporomandibular joint pain, recurrent infections in the external auditory canal, ear buzzing, conductive auditory loss and salivary secretion into the external auditory canal [2].

Spontaneous hernia of the condylar head of the external auditory canal through FH is extremely rare, with approximately 30 cases being reported in the literature [6]. In symptomatic cases, the treatment of $\mathrm{FH}$ requires the defect to be closed in order to prevent prolapse of periarticular tissue in the external auditory canal [7].

In the literature, there are other works assessing the prevalence of $\mathrm{FH}$ by using computed tomography (CT), but a few ones aimed at the Brazilian population by using cone beam computed tomography (CBCT). In this context, the objective of the present study was to assess the prevalence of $\mathrm{FH}$ in a Brazilian population by means of CBCT analysis of examinations selected from an oral radiology clinic's archive.

\section{MATERIAL \& METHODS}

After approval of the study by the local human research ethics committee (CAAE 67664017.7.0000.0077), 599 CBCT examinations from both male and female patients of different ages were selected from an oral radiology clinic's archive of a public teaching institution (ICT-UNESP). All tomographs were acquired with an I-CAT CBCT scanner (Next Generation, Imaging Science International, Hatfield, PA, USA) operating at voxel size of $0.25 \mathrm{~mm}$, field of view (FoV) encompassing the mid-third of the face (6.0 to $8.0-\mathrm{cm}$ height ) and diameter of $16.0 \mathrm{~cm}$. A total of 296 examinations were disregarded because they had no FOV allowing unilateral evaluation of the TMJ, nor showing full TMJ completely. In this way, the final sample consisted of 303 
CBCT examinations (i.e. 606 TMJs). In the present study, we have used no representative sample of the Brazilian population because of the impossibility of obtaining a corresponding number of examinations. Therefore, a convenience sample was used.

After previously selecting the sample, all the images were analysed by using XORAN software (Xoran Technologies, Ann Arbor, Michigan, USA) on a multiplanar reconstruction window, in which the entire tympanic region (right and left) was individually scanned in the antero-posterior orientation through axial sections in order to verify the presence of FH (Figure 1).

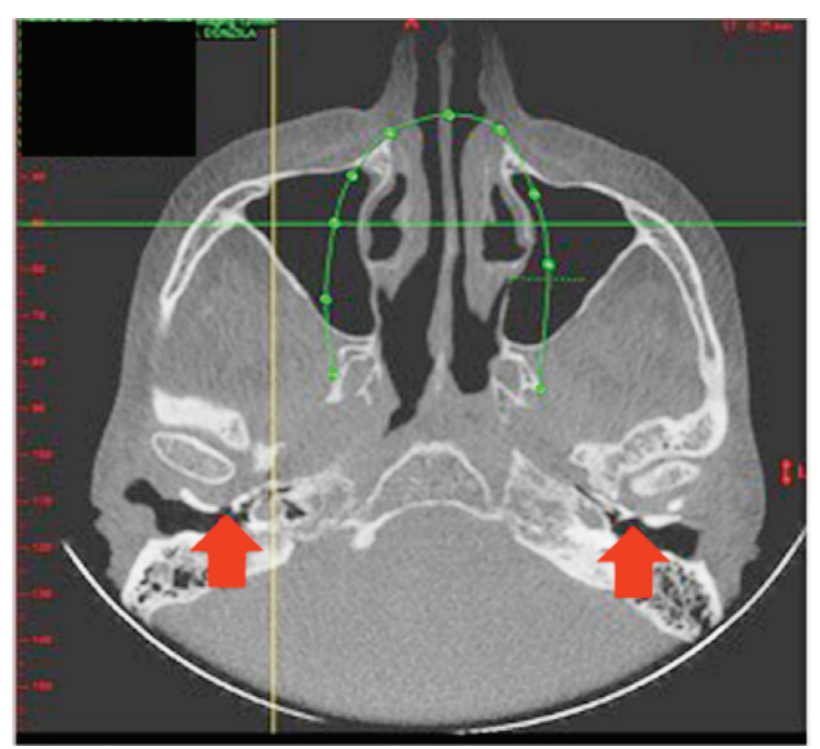

Figure 1 - Axial image showing presence of foramen of Huschke bilaterally (arrows). Source: by the author.

The images were assessed by two previously calibrated examiners regarding the presence or absence of the foramen. Kappa-Cohen test was used to determine the intra- and inter-rater reliabilities, whose values were 0.75 and 0.80 , respectively, which corresponded to very good results.

Image evaluation was performed by using a LCD 19-inch screen with 1280 x 800 pixel resolution in a darkened environment, thus allowing application of enhancement filters (sharpness), zoom and adjustment of brightness and contrast whenever needed. The resulting data were entered into Microsoft Excel spreadsheet for descriptive analysis.

\section{RESULTS}

Considering the number of individuals and number of cases of TMJ, the distribution of the sample regarding gender indicated that $118(38.94 \%)$ individuals were male and 185 (61.06\%) were female, for 236 and 370 TMJs, respectively.

Table 1 lists the distribution of the sample regarding seven age groups.

Table 1 - Sample distribution regarding the age groups studied.

\begin{tabular}{|c|c|c|c|}
\hline $\begin{array}{c}\text { Age } \\
\text { groups } \\
\text { (years) }\end{array}$ & $\begin{array}{l}\text { Male } \\
\text { N (\%) }\end{array}$ & $\begin{array}{c}\text { Female } \\
\text { N(\%) }\end{array}$ & $\begin{array}{l}\text { Total } \\
\mathbf{N}(\%)\end{array}$ \\
\hline $0-20$ & 16 (5.28) & $11(3.64)$ & 27 (8.92) \\
\hline $21-30$ & $14(4,2)$ & $25(8.25)$ & $39(12.87)$ \\
\hline $31-40$ & $21(6.93)$ & $25(8.25)$ & 46 (15.18) \\
\hline $41-50$ & $20(6.60)$ & 44 (14.52) & 64 (21.12) \\
\hline $51-60$ & $26(8.58)$ & 44 (14.52) & $70(23.10)$ \\
\hline $61-70$ & $15(4.95)$ & $22(7.26)$ & $37(12.21)$ \\
\hline Above 70 & $6(1.98)$ & $14(4.62)$ & $20(6.60)$ \\
\hline Total & $118(38.94)$ & $185(61.06)$ & $100(100)$ \\
\hline
\end{tabular}

Table 2 lists the distribution of the presence of FH considering age groups, gender and affected side (i.e. right/left). In our study, we have opted for dividing the sample into right and left sides in order to assess the prevalence of $\mathrm{FH}$ in more details, showing a possible predominance of one of the sides as other prior studies have not considered this variable.

Table 2 - Distribution of the presence of $\mathrm{FH}$ regarding age group and gender in the sample studied. *bilateral in the same individual.

\begin{tabular}{|cccccc|}
\hline \multicolumn{3}{c}{ Male } & & \multicolumn{3}{c|}{ Female } \\
$\begin{array}{c}\text { Age } \\
\text { groups } \\
\text { (years) }\end{array}$ & RightTMJ RightTMJ & RightTMJ RightTMJ & Total \\
\hline $0-20$ & $2(0.33 \%)$ & $0(0.0 \%)$ & $0(0 \%)$ & $0(0.0 \%)$ & $2(0.33 \%)$ \\
\hline $21-30$ & $0(0.0 \%)$ & $0(0.0 \%)$ & $0(0.0 \%)$ & $0(0.0 \%)$ & $0(0.0 \%)$ \\
\hline $31-40$ & $0(0.0 \%)$ & $0(0.0 \%)$ & $0(0.0 \%)$ & $0(0.0 \%)$ & $0(0.0 \%)$ \\
\hline $41-50$ & $0(0.0 \%)$ & $0(0.0 \%)$ & $1(0.16 \%)$ & $1(0.16 \%)$ & $2(0.33 \%)$ \\
\hline $51-60$ & $1(0.16 \%)^{*}$ & $1(0.16 \%)^{\star}$ & $1(0.16 \%)^{*}$ & $1(0.16 \%)^{*}$ & $4(0.66 \%)$ \\
\hline $61-70$ & $1(0.16 \%)$ & $0(0.0 \%)$ & $0(0.0 \%)$ & $1(0.16 \%)$ & $2(0.33 \%)$ \\
\hline Above 70 & $0(0.0 \%)$ & $0(0.0 \%)$ & $2(0.33 \%)^{\star}$ & $2(0.33 \%)^{\star}$ & $4(0.66 \%)$ \\
\hline Total & $4(0.65 \%)$ & $1(0.16 \%)$ & $4(0.65 \%)$ & $5(0.81 \%)$ & $14(2.27 \%)$ \\
\hline
\end{tabular}




\section{DISCUSSION}

The persistence of $\mathrm{FH}$ is a normal anatomical variant of the temporal bone, being an osseous defect in the antero-inferior wall of the external auditory conduct and usually identified after 5 years of age [1]. Several factors have influence on the closure of the $\mathrm{FH}$, such as pressure on the head of the mandible against the tympanic part of the temporal bone during movements of mastication, deglutition and breathing following birth [5].

The importance of the present study is based on cases in which FH might be a factor contributing to the development of problems such as otalgia, TMJ pain, infections in the external auditory conduct, progressive auditory loss, and leakage of saliva into the external auditory conduct with formation of fistulas, in addition to herniation of TMJ $[7,16]$.

Based on this importance, some prior studies have been performed with the aim to investigate the prevalence of FH. This study is grounded on the use of cone beam computed tomography for identification of $\mathrm{FH}$ in a Brazilian population sample, which justifies its importance. In addition, this evidences the need to fully examine the total volume acquired in a tomographic examination for dental purposes only, such as implant planning and evaluation of included teeth, meaning that dental practitioners need to increase their anatomical knowledge on the region of head and neck.

Considering the sample total of 606 TMJs (i.e. 303 CBCT examinations) in our study, there was a prevalence of 14 cases of FH (2.27\%) (Table 2). Prior studies aiming to assess the prevalence of $\mathrm{FH}$ found frequencies ranging from $16 \%$ [8] to $7.2 \%$ [9], $9.93 \%$ [10], $4.6 \%$ [11], $5.0 \%$ to $46.0 \%$ [12], $1.5 \%$ [13], 12.0 to $14.0 \%$ [1] and $4.4 \%$ [14]. Comparatively, our work has found a frequency lower than those reported by other studies, but all of them had considered the presence or absence of FT anatomically, that is, through macroscopic inspection of macerated skulls. But their methodology differs from ours as we have analysed CBCT tomographs.

Some of the above-cited studies, such as
Rezaian et al. (2015), examined skulls from archaeological excavation in Iran and this might have led to erroneous identification of the structures. We believe that cone beam computed tomography (CBCT) can be a more reliable for identification of the persistence of FT as it is a more recent method than other imaging modalities, such as conventional radiography and fan beam computed tomography (FBCT), even providing a significant radiation reduction to the patient compared to the latter. Moreover, CBCT provides high-resolution images of bone tissues with submillimetric sections and no overlapping of structures, in addition to enabling the same structure to be viewed in different anatomical planes.

Considering the side affected by the presence of FT (i.e. right side, left side or bilateral), we have found that $0.65 \%$ of our sample had unilateral cases, whereas $1.62 \%$ involved bilateral cases in the total (Table 4). Of the unilateral cases, it was found that $0.49 \%$ belonged to the right side among males and $0.16 \%$ belonged to the left side among females. Of the bilateral cases, $0.32 \%$ belonged to males and $1.30 \%$ to females (Table 4), that is, the majority of females were bilateral. In the literature, we have found that some studies assessing the prevalence of FT also indicated the most affected sides. For instance, a study [15] reported prevalences of $11.6 \%$ and $6.3 \%$, respectively, for unilateral and bilateral $\mathrm{FH}$, a finding different from ours as we found a higher prevalence of bilateral FH (1.62\%). However, it should be emphasised that that study [15] was the first one to assess the prevalence of $\mathrm{FH}$ by using CBCT scanner operating at a resolution of $0.30 \mathrm{~mm}$, whereas we used tomographs with higher resolution (i.e. $0.25 \mathrm{~mm}$ at maximum). However, one cannot state that this difference in image resolution between that study [15] and ours had affected the capacity of identifying the $\mathrm{FH}$, thus resulting in the difference between the results. We believe that this may not be a determining factor, since the mean dimensions of FT reported in the literature range between $2.7 \mathrm{~mm}$ in length and $2.0 \mathrm{~mm}$ in width for males and $2.8 \mathrm{~mm}$ in length and $2.2 \mathrm{~mm}$ in width for females. These measurements have an order of magnitude where a variation from $0.25 \mathrm{~mm}$ to $0.30 \mathrm{~mm}$ may not be significant. 
Still, as for the affected side, another study [11] used a sample of 65 human skulls (130 temporal bones) and found a prevalence of 4 unilateral and 2 bilateral cases of $\mathrm{FH}$. Instead of using a macroscopic inspection method, the authors used FBCT images of skulls acquired with a voxel size of $0.21 \mathrm{~mm}$, that is, an image resolution higher than that in our study. In any way, further studies on the impact of voxel size variation on the spatial resolution of CT images for detection of FT should be conducted so that its actual influence could be assessed.

We have also found in the literature a study [5] assessing the presence of FT in 93 skulls (34 temporal bones), showing prevalences of $16.22 \%$ and $22.02 \%$ for unilateral FT on the right and left sides, respectively. Bilateral FT was found in 13.98\% of the cases and presence of multiple FHs on the same side in $5.91 \%$ of their sample. These results are also different from ours, since we found a higher percentage $(1.62 \%)$ of bilateral FTs, with the majority $(0.49 \%$ of the sample) being on the right side rather than on the left side. Moreover, no multiple FTs were found in our sample either. Other authors [10] obtained results which can corroborate our findings, since they reported that $53 \%$ of the FTs were unilateral and $46.8 \%$ were bilateral. Their results are coincident with ours regarding the higher prevalence of unilateral FTs, even with less discrepant frequencies. Another study [14] examined 45 skulls and found a prevalence of $4.4 \%$ for bilateral FTs only.

In our study, we have observed a higher prevalence of FT in females than in males, respectively, $1.46 \%$ and $0.81 \%$ of the sample. With regard to gender, we found in the literature a study [11] reporting that six of the FTs found in their sample, four belonged to females, which corroborates our findings on the higher prevalence in women. Other authors [10] also emphasise that FTs affect mostly black women. Among the studies reviewed here, there was none focused on the distribution of persistent FT by gender and by age group. Nevertheless, we have observed clinical cases of symptomatic patients complaining of TMJ pain, limitation of oral opening, presence of otitis and auditory loss in which persistent FT was discovered, with herniation into the external auditory conduct as a result. In two studies $[3,6]$, the patients were male and aged between 28 and 54 years old, whereas only one study [7] reported a case of symptomatic 48-year-old female with FT.

It is difficult to address the prevalence of FT by age group because the studies [5, $8,10]$ found in the literature, among others, were performed in human skulls without any chronological age group being established. In our study, we can demonstrate that FT was more prevalent in males aged between 0 and 20 years old $(0.33 \%)$ and in females older than 70 years $(0.66 \%)$ (Table 4$)$. One can observe a high prevalence in the age group of 51-60 years for both genders regarding bilateral FTs, with a total value of $2.27 \%$ (0.32\% each). By addressing age and its relationship with the prevalence of FT, other authors [1] state that FT is less likely to persist as individuals get older, which may even result in foraminal occlusion. This fact contradicts our findings on females as we found a frequency of $0.66 \%$ and age group above 70 years old.

\section{CONCLUSION}

Considering the methodology of the present study, we can conclude that the foramen of Huschke had a prevalence of $2.27 \%$ in our sample, with $0.65 \%$ being unilateral and $1.62 \%$ bilateral cases. In our sample, females were more affected than males, respectively $1.46 \%$ and $0.81 \%$.

\section{REFERENCES}

1. Hashimoto T., Ojiri H., Kawai Y. The Foramen of Huschke: age and tender specific features after childhood. J Oral Maxillofac Surg. 2011; 40: 743-746.

2. Reis, Henrique Nogueira et al. Persistência do forame de Huschke:Um estudo tomográfico. Radiologia Brasileira. 2006;39(4):273-6.

3. Olarinoye-Akorede S.A, Olanrewaju I.S, Suleiman A.O. Foramen of Huschke (Tympanicum) I na Nigerian male with articular soft-tissue hernation into the external auditory meatus. Ann Afr Med 2014;13:226-8.

4. Fusconi M, Benfari G, Franco M, Deriu D, Dambrosio F, Greco A, Ciotti M, Colicchio MG, de Vincentiis M. Foramen of Huschke: case report and experimental procedure for diagnosis of spontaneous salivary fistula. J Oral Maxillofac Surg. 2009 Aug;67(8):1747-51. doi: 10.1016/j.joms.2008.12.065.

5. Sankar KD, Bhanu PS. Incidence of Foramen of Huschke in South Andhra Population of India. J Clin Diagn Res. 2016 Jun;10(6):AC01-3. Epub 2016 Jun 1.

6. Shapiro MC, Osborn T. Temporoparietal fascia flap and total temporomandibular joint replacement for the management of patent foramen of Huschke. Int J Oral Maxillofac Surg. 2016 Aug;45(8):1023-6. Epub 2016 Apr 8 
7. Akcam T,Hidir Y,llica AT, Kilic E, Sencimen M. Temporomandibular joint herniation into the external ear canal through foramen of Huschke. Auris Nasus Larynx. 20110ct;38(5):646-9. Epub 2011Feb 12.

8. Herzog S, Fiese R.Persistent Foramen of Huschke: Possible Risk Factor for Otologic Complications After Arthroscopy of the Temporomandibular Joint. Oral Surg Oral Med Oral Pathol 1989;68:267-70.

9. Wang RG, Bingham B, Hawke M, Kwok P,LiJR.Persistence of the foramen of Huschke in the adult: an osteological study. J Otolaryngol 1991; 20:251-253.

10. Faig-Leite H, Horta Júnior JAC. Persistence of the foramen of Huschke. Dent Res 1999;77:177.

11. Lacout A, Marsot-Dupuch K, Smoker WR, Lasjaunias P. Foramen Tympanicum, or Foramen of Huschke: pathologic cases and anatomic CT study. AJNR Am J Neuroradiol. 2005;26:1317-23.
12. Rushton VE, Pemberton MN. Salivary otorrhoea: a case report and a review of the literature. Dentomaxillofac Radiol 2005;34:376-379.

13. Park YH, Kim HJ, Park MH. Temporomandibular joint herniation into the external auditory canal. Laryngoscope. 2010:1184-8.

14. Rezaian J, Namavar M.R, Nasab H.V,Nobari A.R.H, Abedollahi A. Foramen Tympanicum or Foramen of Huschke: a Bioarcheological Study of Humans Skeletons from an Iron Age Cemitery at Tabriz Kabud Mosque Zone.. Iran J Med Sci. 2015 Jul;40(4):367-71.

15. Tozoglu U,Caglayan F,Harorli A. Foramen tympanicum or foramen of Huschke: anatomical cone beam CT study. Dentomaxillofac Radiol. 2012 May;41(4):294-7.

16. Lee YW, Park YH. Bilateral spontaneous symptomatic temporomandibular joint herniation into the external auditory canal: a case report and literature review. Auris Nasus Larynx.. 2018 Apr;45(2):346-350.

\section{Sérgio Lúcio Pereira de Castro Lopes}

(Corresponding address)

Avenida Eng. Francisco José Longo, $\mathrm{n}^{\circ} 777$

Jardim São Dimas - CEP - 12245-000

São José dos Campos, SP

Date submitted: 2018 Jan 09

E-mail: sergio.lopes@fosjc.unesp.br 